Editorial

\section{The Newly Garbed VCOT}

Kenneth A. Johnson ${ }^{1}$

1 Professor and Director of Orthopaedics, Sydney School of Veterinary Science, University of Sydney, Sydney, New South Wales, Australia

Vet Comp Orthop Traumatol 2019;32:v.

In 2018, Veterinary and Comparative Orthopaedics and Traumatology underwent a smooth transition over to our new publisher Thieme, with modernization of our Journal style and format in such things as column width and referencing, for example. Now with the start of a new year, the print version of the Journal has made a complete break with tradition, appearing with a striking blue cover - this being the "house colours" of other Thieme journals. We hope you admire the newly garbed VCOT!

The editorial team of VCOT extend our sincere appreciation to all of our authors and reviewers who have worked together to bring our readers a huge array of informative and interesting new data in the articles published in the past six issues of 2018. It is only with the support of our authors, reviewers, readers, corporate sponsors and official societies that we grow and improve. We thank you.

Wishing you the very best for the new year ahead.

\section{Sincerely}

Kenneth A. Johnson

Editor-in-Chief, VCOT

Sydney, Australia

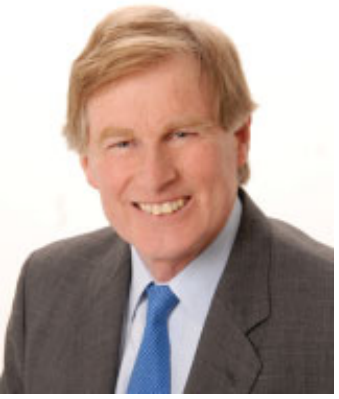

Kenneth A. Johnson
Address for correspondence Professor Kenneth A. Johnson, MVSc, PhD, DACVS, DECVS, Sydney School of Veterinary Science, University of Sydney, Sydney, New South Wales, Australia

(e-mail: kenneth.johnson@sydney.edu.au). (c) 2019 Georg Thieme Verlag KG Stuttgart · New York
DOI https://doi.org/

10.1055/s-0038-1677021. ISSN 0932-0814. 